\title{
Nutrition Campaign Knowledge and Dietary Behavior in Middle School Students
}

\author{
Sarah E. Roth ${ }^{1}$, Monique Gill ${ }^{1}$, Alec M. Chan-Golston ${ }^{2}$, Catherine M. Crespi ${ }^{2}$, Stephanie L. \\ Albert $^{3}$, Lindsay N. Rice ${ }^{1}$, and Michael L. Prelip ${ }^{1}$ \\ ${ }^{1}$ Department of Community Health Sciences, UCLA Fielding School of Public \\ ${ }^{2}$ Department of Biostatistics, UCLA Fielding School of Public Health \\ ${ }^{3}$ Department of Population Health, New York University School of Medicine
}

\begin{abstract}
Background and Purpose: Federal nutrition campaigns are designed to make dietary recommendations accessible but have not been extensively evaluated. This paper explores whether knowledge of nutrition campaigns is associated with dietary behavior among young adolescents. Methods: Cross-sectional survey data were collected from 4,773 middle school students in Southern California. Hierarchical logistic regression models were used to assess the association between dietary behaviors and nutrition campaign knowledge, controlling for gender and ethnicity. Results: Knowledge of the Fruit \& VeggiesMore Matters campaign was associated with increased odds of high fruit and vegetable consumption, knowledge of the MyPlate campaign was associated with neither, and both were associated with increased odds of not consuming soda. Conclusion: Overall, low percentages of students demonstrated knowledge of nutrition campaigns, and knowledge was associated with some dietary behaviors. More research is needed to examine the impact of nutrition campaigns while also accounting for other psychosocial and environmental factors that may affect soda, fruit, and vegetable consumption.
\end{abstract}

(C) 2018 Californian Journal of Health Promotion. All rights reserved.

Keywords: Adolescent Health, Nutrition Policy, Latinos, Diet, Health Promotion

\section{Introduction}

A substantial body of literature has identified the important role of diet in the prevention of obesity and chronic diseases which remain leading causes of morbidity and mortality in the United States (Dietz, Douglas, \& Brownson, 2016; Johnson et al., 2014; World Health Organization, 2003). Establishing healthy dietary habits in adolescence is important because eating behaviors often track into adulthood (Movassagh, Baxter-Jones, Kontulainen, Whiting, \& Vatanparast, 2017). However, overall diet quality of adolescents remains poor consisting of diets low in fruit and vegetable consumption and an excess of energyrich, nutrient-poor foods and beverages, such as soda (Gu \& Tucker, 2016; Kimmons, Gillespie, Seymour, Serdula, \& Michels Blanck, 2009; Reedy \& Krebs-Smith, 2010).

A number of factors including nutrition knowledge play an important role in influencing adolescent eating behavior (Pirouznia, 2001; Rimer \& Glanz, 2005). The federal government

has developed dietary guidelines to increase nutrition knowledge and shape the public's diet (Haack \& Byker, 2014). The United States Departments of Agriculture (USDA) and Health and Human Services (USDHHS) release the Dietary Guidelines for Americans (DGA) every five years to promote diet knowledge for health promotion and disease prevention (Kennedy, Meyers, \& Layden, 1996). To make dietary recommendations more accessible and applicable for daily food intake, federal nutrition campaigns have been designed and disseminated over the past three decades. Dissemination of these campaigns has included communications initiatives that message across multiple channels, the development of websites with interactive features and resources for consumers, health professionals, and educations; as well as partnerships with a range of like-minded groups and institutions (e.g., health associations, 
research institutions, media outlets and food industry representatives) (Levine, AbbatangeloGray, Mobley, McLaughlin, \& Herzog, 2012). One such campaign, MyPlate, offers a simple visual representation of a balanced meal that includes fruits, vegetables, protein, grains, and dairy (US Department of Agriculture Food and Nutrition Service., 2012). MyPlate's graphic properties and its visual comparability to a reallife plate make it, at least in theory, an easily understood educational tool adeptly targeted for youth nutrition education (Post, 2011). Another important federal nutrition campaign, Fruits \& Veggies - More Matters (More Matters), promotes increased fruit and vegetable intake by advocating for at least five or more servings of fruits and vegetables per day (Pivonka, Seymour, McKenna, Baxter, \& Williams, 2011; Produce for Better Health Foundation, Centers for Disease Control \& Prevention, 2007).

Although widely disseminated through print (e.g., brochures, advertisements in grocery stores, and food package labels) and online materials (e.g., websites and social media channels), the effectiveness of these federal nutrition education programs in terms of their relationship to diet behaviors has not been extensively evaluated (Erinosho, Moser, Oh, Nebeling, \& Yaroch, 2012; Tagtow \& Raghavan, 2017; Wojcicki \& Heyman, 2012). Furthermore, few studies have examined knowledge of nutrition campaigns among children and adolescents. In nationally representative studies of adolescents, only $30.6 \%$ of adolescents surveyed were aware of the My Plate program, while $43.5 \%$ of youth surveyed were aware of the More Matters program (Tagtow \& Raghavan, 2017; Wojcicki \& Heyman, 2012). These studies also found significant differences in awareness levels by race and ethnicity with lowest levels of awareness reported by Mexican-American participants (Tagtow \& Raghavan, 2017; Wojcicki \& Heyman, 2012).

While it is evident that diet quality is lacking, it is unknown if adolescents know what experts recommend and whether this knowledge affects their dietary behavior. Studies of older adolescents in high school and college have demonstrated associations between dietary behaviors and nutrition knowledge, indicating a positive relationship between higher nutrition campaign knowledge and a more healthful eating pattern (Kolodinsky, Harvey-Berino, Berlin, Johnson, \& Reynolds, 2007; Rafiroiu, Anderson, Sargent, \& Evans, 2002). However, to our knowledge no studies have examined the relationship between nutrition campaign knowledge and diet among younger adolescents in middle school despite the significance of this developmental period for establishing lifelong healthy diet habits (Demory-Luce et al., 2004) It remains unclear how widespread campaigns such as MyPlate and More Matters, may contribute to dietary behavior in youth, particularly among young adolescents. In this study we explore the connection between dietary behavior and nutrition campaign knowledge among a sample of predominantly Latinx middle school students in Los Angeles County.

\section{Methods}

\section{Participants and Recruitment}

Data were collected from a cross-sectional survey of seventh grade students from 16 middle schools in a large, urban school district in Fall 2014. This survey was conducted as part of a larger physical education (PE) intervention study. PE teacher participation in the study was voluntary. Of the 6,201 seventh-grade students at all study schools, 5,529 students were enrolled in participating teachers' classes (89.2\%), and 4,773 students completed the survey (77.0\%). Schools were located in low-income, racially and ethnically diverse communities. On average, $74 \%$ of students enrolled in participating schools were eligible for the free or reduced-price lunch program. Participation in the survey was open to all seventh-grade students enrolled in physical education (PE), and details of the study and passive consent forms were distributed to parents/caregivers prior to administration of the survey allowing them to opt out. The research team notified parents/caregivers and students that participation was voluntary and would not affect their academic grades. Students provided their verbal assent to participate. The survey instrument was pretested with 18 students (9 males, 9 females; 6-6th grade, 12-7th grade). 
Minor modifications were made to improve parsimony and clarity and then retested with nine additional students (5 males, 4 females). The study was approved by university and school district institutional review boards.

\section{Measures}

Knowledge was assessed using pretested items developed by the research team. The following three questions were used to assess MyPlate knowledge: "How much of the plate in a typical meal should be fruits and vegetables?", "How much of the plate in a typical meal should be grains such as rice, bread, or oats?", and "How much of the plate in a typical meal should be proteins such as meat, poultry, or seafood?" The response options were: "1//8", “1/4", "1/2", "the whole plate", and "I don't know." For each question, the responses were dichotomized as correct based on MyPlate visual dietary recommendations with " $1 / 2$ " labeled as correct for fruit and vegetable item; " $1 / 4$ " labeled as correct for both the meat and grains items, and any other response labeled incorrect. "I don't know" was also categorized as incorrect. MyPlate responses were tabulated as either all three items correct or not. Although Federal dietary recommendations vary based on gender, age, and activity level, messages about how one's plate should look are embedded within the MyPlate visual (Post, 2011). Knowledge of More Matters was assessed using one item: "How many servings of fruits and vegetables a day do you think teens are supposed to eat?". Response options were "0”, “1-3”, “4-6”, “7-9”, "10 or more", and "I don't know." Responses were dichotomized with "4-6", "7-9", and "10 or more” labeled as correct, and any other response labeled incorrect.

Three survey items, adapted from the Youth Risk Behavior Survey 2013 (Centers for Disease Control and Prevention, 2015) were used to assess frequency of consumption of fruit, vegetables (excluding potatoes), and regular or diet soda during the past 7 days. For each item fruit, vegetable, and soda consumption - students could select one of the following responses: "I did not drink/eat this during the past 7 days", "1 to 3 times during the past 7 days", " 4 to 6 times during the past 7 days", "1 time per day", "2 times per day”, “3 times per day”, or " 4 or more times per day." Fruit and vegetable intake were dichotomized into high or low consumption, with high defined as consuming 3 or more per day for both fruit and vegetable categories. Soda behavior was dichotomized into no consumption versus any consumption. Gender and ethnicity (Latinx and Non-Latinx) were self-reported by students.

\section{Data Analyses}

Analyses were conducted using Stata version 14.1 (StataCorp, 2015). Descriptive statistics were calculated for the full sample. To account for clustering of students within schools, hierarchical logistic regression models with random intercepts for school were used to test for differences in demographic characteristics by the dichotomized nutrition campaign knowledge questions. Next, hierarchical multivariable logistic regression models were used to assess the association between the dichotomized dietary behaviors and nutrition campaign knowledge, controlling for gender and ethnicity. These models can be written as $\operatorname{logit}\left[p\left(\mathrm{y}_{\mathrm{ij}} \mid \mathrm{x}_{\mathrm{ij}}\right)\right]=$ $\alpha_{\mathrm{i}}+\beta \mathrm{x}_{\mathrm{ij}}$, where $\operatorname{logit}(\mathrm{q})=\ln [\mathrm{q} /(1-\mathrm{q})], \mathrm{y}_{\mathrm{ij}}$ and $\mathrm{x}_{\mathrm{ij}}$ are observations in the $i^{\text {th }}$ of $j^{\text {th }}$ student, $\beta$ is a vector with elements equal to the number of estimated fixed effects, and $\alpha_{\mathrm{i}}$ are a random intercept term mean to capture variability within school. All $\alpha_{\mathrm{i}}$ 's are assumed to be independent of each other and for a given school $i, \alpha_{\mathrm{i}}$ follows a normal distribution centered at a grand mean of $\alpha$ and school-specific variance $\sigma_{\mathrm{s}}{ }^{2}$. This variance, $\sigma_{\mathrm{s}}{ }^{2}$, can be thought of as the variance of the school means. For each multivariable model, a likelihood ratio test was used to test if the addition of the random intercepts significantly improved the fit of the model (compared to a simpler model replacing $\alpha_{\mathrm{i}}$ with $\alpha)$.

\section{Results}

Table 1 presents sample characteristics and differences in demographics and reported behaviors by nutrition campaign knowledge. Half of the students surveyed were female and $69.5 \%$ identified as Latinx. Only $16.7 \%$ students reported eating fruit 3 or more times a day and an even lower percentage consumed 3 or more 
vegetables per day (10.6\%). A majority of the previous week. students (69.8\%) reported drinking some soda in

\section{Table 1.}

Demographic Characteristics and Dietary Behaviors for Full Sample and by Nutrition Campaign Knowledge

\begin{tabular}{|c|c|c|c|c|c|}
\hline \multirow[b]{2}{*}{ Characteristics } & \multirow{2}{*}{$\begin{array}{l}\begin{array}{l}\text { Total } \\
\text { Percent }\end{array} \\
(n=4,773)\end{array}$} & \multicolumn{2}{|c|}{$\begin{array}{l}\text { Answered All MyPlate } \\
\text { Questions Correct } \\
\text { Percent }\end{array}$} & \multicolumn{2}{|c|}{$\begin{array}{l}\text { Answered More Matters } \\
\text { Question Correct } \\
\text { Percent }\end{array}$} \\
\hline & & $\begin{array}{l}\text { No } \\
(\mathrm{n}=4,237)\end{array}$ & $\begin{array}{l}\text { Yes } \\
(\mathrm{n}=387)^{2}\end{array}$ & $\begin{array}{l}\text { No } \\
(\mathrm{n}=2,493)\end{array}$ & $\begin{array}{l}\text { Yes } \\
(\mathrm{n}=2,256)\end{array}$ \\
\hline
\end{tabular}

Gender

$\begin{array}{lccccc}\text { Male } & 50.0 & 91.3 & 8.7 & 49.91 & 50.1^{* * *} \\ \text { Female } & 50.0 & 91.8 & 8.2 & 55.1 & 44.9 \\ \text { Ethnicity } & & & & & \\ \text { Latinx } & 69.5 & 91.9 & 8.1 & 49.6 & 50.4 \\ \text { Non-Latinx } & 30.5 & 90.5 & 9.5 & 53.5 & 46.5 \\ \text { Fruit } & & & & & \\ \text { High } & & & & & \\ \text { Low } & 16.7 & 91.7 & 8.3 & 37.1 & 62.9 * * * \\ & 83.3 & 91.6 & 8.4 & 55.5 & 44.6\end{array}$

Vegetables

$\begin{array}{llllll}\text { High }^{1} & 10.6 & 91.8 & 8.2 & 53.1 & 46.9 \\ \text { Low } & 89.4 & 91.6 & 8.4 & 57.0 & 43.0 \\ \text { None } & 30.2 & 89.0 & 11.0^{* * *} & 48.6 & 51.4^{* * *} \\ \text { Any } & 69.8 & 92.7 & 7.3 & 54.1 & 45.9\end{array}$

${ }^{*} \mathrm{p}<0.05,{ }^{* *} \mathrm{p}<0.01,{ }^{* * *} \mathrm{p}<0.001$; Significant differences in MyPlate answers by characteristics were tested using Wald tests in hierarchical logistic regression models that included random

intercepts for schools. Sample sizes used in calculating statistics may be smaller due to missing data in the characteristics. ${ }^{1}$ High fruit and vegetable consumptions were defined as 3 or more a day. Low fruit and vegetable consumptions were defined as less than 3 a day.
Overall, only $8.4 \%$ answered all three MyPlate questions correctly with $26.2 \%, 45.8 \%$, and $39.9 \%$ answering the fruit and vegetable, grains, and protein serving recommendation questions correctly, respectively (not shown). With regard to the More Matters measure, $47.5 \%$ answered correctly. While no differences were observed 
by gender or ethnicity in MyPlate responses, males were slightly more likely to answer the More Matters item correctly. A significantly higher proportion of students who incorrectly answered one or more of the MyPlate questions reported drinking soda compared to students who answered all questions correctly (92.7\% vs. 7.3\%; p < 0.001). A similar association was observed in answering the More Matters question correctly and reporting drinking any soda $(54.1 \%$ vs. $45.9 \% ; \mathrm{p}<0.001)$.
Additionally, a significantly higher proportion of students who answered the More Matters question correctly reported high fruit consumption, defined as eating fruit 3 or more times per day (37.1\% vs. 62.9\%; $\mathrm{p}<0.001)$. However, this effect was not seen with answering the three MyPlate questions correctly. No differences were seen in reported consumption of vegetables with knowledge of either MyPlate or More Matters servings recommendations.

Table 2.

Hierarchical Logistic Regression Results of Fruit and Vegetable Consumption

\begin{tabular}{llll}
\hline & $\begin{array}{l}\text { High Fruit } \\
\text { Consumption } \\
(\mathrm{n}=4,146)\end{array}$ & $\begin{array}{l}\text { High Vegetable } \\
\text { Consumption } \\
(\mathrm{n}=4,138)\end{array}$ & $\begin{array}{l}\text { No Soda } \\
\text { Consumption } \\
(\mathrm{n}=4,122)\end{array}$ \\
\hline Coefficients & OR $(95 \% \mathrm{CI})$ & OR $(95 \% \mathrm{CI})$ & OR (95\% CI) \\
\hline
\end{tabular}

Fixed Effects

Female

$0.89(0.75,1.05)$

$0.80(0.64,0.97) *$

$1.29(1.12,1.47)^{* * *}$

Latinx

$0.84(0.70,1.01)$

$0.69(0.56,0.86)^{* *}$

$0.68(0.58,0.79)^{* * *}$

All MyPlate Questions Correct $0.80(0.59,1.09)$

$0.92(0.64,1.33) \quad 1.51(1.20,1.89)^{* * *}$

More Matters Question Correct $2.06(1.74,2.44)^{* * *}$

$1.60(1.31,1.97)^{* * *} \quad 1.18(1.03,1.35)^{*}$

\section{Random Effects}

$\begin{array}{llll}\text { School Level Error Std. Dev } & 0.12 & 0.00 & 0.21^{* * *} \\ \text { Wald } \chi^{2} & 77.96(4)^{* * *} & 39.61(4)^{* * *} & 53.83(4)^{* * *}\end{array}$

${ }^{*} \mathrm{p}<0.05,{ }^{* *} \mathrm{p}<0.01,{ }^{* * *}, \mathrm{p}<0.001 ;{ }^{1}$ High fruit and vegetable consumptions were defined as 3 or more a day. Low fruit and vegetable consumptions were defined as less than 3 a day. ${ }^{2}$ Significance of school level error variance was tested using likelihood ratio tests.

Table 2 presents results of the hierarchical multivariable logistic regression models predicting healthy dietary behaviors. Females had 29\% increased odds (OR=1.29; 95\% CI $1.12,1.47)$ of reporting no soda consumption and $20 \%$ decreased odds (OR $=0.80 ; 95 \%$ CI $0.64,0.97$ ) of reporting high vegetable consumption compared to their male peers, controlling for ethnicity and nutrition campaign knowledge. All else equal, Latinx students had $32 \%$ decreased odds $(\mathrm{OR}=0.68$; 95\% CI 0.58 ,
0.79) of reporting no soda consumption and 31\% decreased odds

(OR=0.69; 95\% CI 0.56, 0.86) of reporting high vegetable consumption compared to their nonLatinx counterparts. MyPlate knowledge did not demonstrate a relationship with either fruit or vegetables consumption. However, students who answered all three of the MyPlate questions correctly had $51 \%$ increased odds ( $\mathrm{OR}=1.51$; $95 \%$ CI 1.20, 1.89) of reporting no soda consumption. Those who correctly responded to 
the More Matters question, however, had higher odds for all three outcomes. Specifically, they had 106\% increased odds (OR=2.06; 95\% CI $1.74,2.44)$ of high reported fruit consumption, $60 \%$ increased odds (OR=1.60; 95\% CI 1.74, 2.44) of high reported vegetable consumption, and $18 \%$ increased odds (OR=1.18; 95\% CI $1.03,1.35$ ) of low reported soda consumption, controlling for gender, ethnicity, and MyPlate responses.

\section{Discussion}

Over the past three decades, multiple federal nutrition campaigns have attempted to convey clear and relatable knowledge of a balanced diet to the public (Haack \& Byker, 2014). However, few studies have examined the association between knowledge of the campaign recommendations and dietary intake, particularly among youth. Because nutritional knowledge has been posited as a key factor affecting dietary behavior, assessing the extent to which adolescents demonstrate knowledge of the recommendations from nutrition campaigns and exploring whether this knowledge is associated with some recommended dietary behaviors may reveal the impact of these efforts. This study examines knowledge of MyPlate and More Matters recommendations and their association with reported consumption of fruit, vegetables, and soda among middle school adolescents.

Findings from this current study suggest that knowledge of campaign recommendations was associated with some dietary behaviors, namely no reported soda consumption. Overall, an underwhelming percentage of students (8.4\%) demonstrated knowledge of MyPlate recommendations for the appropriate amount of fruit, vegetables, grains, and protein in a meal. When looking specifically at the MyPlate fruit and vegetable question, compared to those who answered all three items correctly, a higher, but still low proportion (26.2\%) of students responded correctly. Further, while a greater percentage of students knew the recommended number of servings of fruits and vegetables recommended by the More Matters campaign compared to MyPlate, less than half of the sample (47.5\%) answered the question correctly. These findings suggest that, despite the large- scale roll out for both federal nutrition campaigns, knowledge of dietary recommendations do not reach all youth. This mirrors previous evidence of low awareness of these campaigns among adults and adolescents (Epstein, Jean-Pierre, Lynn, \& Kant, 2013; Tagtow \& Raghavan, 2017; Wojcicki \& Heyman, 2012; Wright \& Wang, 2011). Given the relationship between campaign nutrition knowledge and healthful eating among adults and youth (Rafiroiu et al., 2002; Spronk, Kullen, Burdon, O’Connor, \& Connor, 2014), there is room to increase awareness, understanding, and implementation of the nutrition messages marketed by these campaigns in order to improve dietary choices among young adolescents. The public health significance of these potential changes is enormous given increased rates of adolescent obesity in recent decades (Ogden, Carroll, Kit, \& Flegal, 2014).

Interestingly, both MyPlate and More Matters knowledge were associated with no reported soda consumption. Although the survey items did not directly assess knowledge of sugary drink recommendations, knowledge of healthy dietary recommendations was associated with lower likelihood of this particular unhealthy dietary behavior. As children and adolescents are generally not the primary food purchasers in the household, this finding may reflect the fact that avoiding soda or other unhealthy items is a more feasible behavior than consuming fruits and vegetables that may not be available or accessible to the student. Nonetheless, a conversation on beverages and snack foods that are consumed outside of mealtimes is largely absent from nutrition campaigns for balanced diets (Guthrie, Mancino, \& Lin, 2015).

This study echoes previous findings that fruit and vegetable consumption in adolescent diets is low (Prelip, Kinsler, Thai, Erausquin, \& Slusser, 2012; UCLA Center for Health Policy Research, 2014). Only $16.7 \%$ and $10.6 \%$ of students reported eating three or more fruits and vegetables a day, respectively. Additionally, the results of the study found that female and Latinx students had lower odds of reporting high vegetable consumption than their male and nonLatinx peers, respectively. These findings differ 
from previous evidence indicating that girls have higher and more frequent intake of fruits and vegetables than boys (Rasmussen et al., 2006; Spronk et al., 2014) and Latinx youth have consistently higher fruit and vegetable intake than their non-Latinx White or AfricanAmerican peers (Di Noia \& Byrd-Bredbenner, 2014). Given these findings, more research is needed to examine the efficacy of nutrition campaigns as it relates to dietary behavior among different adolescent groups, while also taking into consideration other determinants of fruit and vegetable consumption. Such determinants could include taste preferences, parental intake, and environmental factors that shape the accessibility and availability of healthy or unhealthy food options (Blanchette \& Brug, 2005; Rasmussen et al., 2006).

\section{Limitations}

This study utilized cross-sectional data collected in one geographic location, which limits the ability to make causal claims or generalize findings. It is possible that rather than campaign knowledge driving behavior, youth who eat healthier may pay more attention to federal nutrition campaigns or may demonstrate higher levels of campaign knowledge because it reflects already established eating habits. However, as diet quality remains low for many adolescents including a large proportion of participants in this study - considering the ways in which nutrition campaigns influences behavior offers a potential pathway for intervention.

In addition, data were self-reported by students, making them susceptible to social desirability and recall bias. Survey items regarding dietary behavior asked about frequency of consumption, but did not capture serving size, which may influence comparability between respondents. Further, the dietary behavior items only included fruit and vegetable consumption as an indicator of healthy eating behavior and soda consumption as an indicator of unhealthy eating behaviors. As previous research suggests ( $\mathrm{Gu} \&$ Tucker, 2016), adolescent diets are characterized by low fruit and vegetable consumption as well as high consumption of unhealthy items such as soda. Therefore, the authors felt it was conceptually important to include both diet behaviors. Due to the answer categories of the questionnaire, our measure of More Matters may overestimate student awareness of the campaign, thus representing an additional limitation of our study. Furthermore, knowledge of MyPlate's recommended beverages, such as milk, was not assessed and thus could not be compared to the beverage consumption behaviors measured. Because students were asked only about knowledge and not familiarity with the campaigns, it is possible that a small proportion of students answered knowledge questions correctly despite not being familiar with the campaigns. In addition, the order of the More Matters, MyPlate, and dietary behavior items was not randomized in the questionnaires potentially resulting in response bias. Socioeconomic factors and literacy levels may also affect the proportion of students who answered nutrition campaign questions correctly.

While nutrition campaigns attempt to simplify nutrition information, the processes of acquiring and applying knowledge from these campaigns can nonetheless be a challenging task for youth (Guthrie et al., 2015). Knowledge is only one of many psychosocial factors relevant to adolescent dietary behavior (Story, Neumark-Sztainer, \& French, 2002). Food choices are also affected by emotional and cognitive factors, and thus the straightforward, or often dull, nature of nutrition information campaigns may be ineffective. Marketing campaign efforts that use more personalized and motivating strategies may be more persuasive than simple visuals (Guthrie et al., 2015). Continued efforts to promote fruit and vegetable intake are needed, including those that seek creative ways to increase consumption in school-aged youth.

In conclusion, this study found that that knowledge of the MyPlate and More Matters campaigns among middle school students was low and that campaign nutrition knowledge is associated with certain dietary behaviors. Overall, findings underscore the need for further examination of the impact of nutrition knowledge campaigns, while considering other factors that may affect dietary consumption in young adolescents. 
Roth, S.E., Gill, M., Chang-Golston, A.M., Crespi, C.M., Albert, S.L., Rice, L.N., Prelin, M.L / Californian Journal of Health

Promotion 2018, Volume 16, Issue 2,Pages 1-10.

\section{References}

Blanchette, L., \& Brug, J. (2005). Determinants of fruit and vegetable consumption among 6-12-year-old children and effective interventions to increase consumption. Journal of Human Nutrition and Dietetics, 18(6), 431-443.

Centers for Disease Control and Prevention. (2015). 2015 Youth Risk Behavior Survey. Retrieved September 9, 2016, from https://www.cdc.gov/healthyyouth/data/yrbs/index.htm

Di Noia, J., \& Byrd-Bredbenner, C. (2014). Determinants of fruit and vegetable intake in low-income children and adolescents. Nutrition Reviews, 72(9), 575-590. https://doi.org/10.1111/nure.12126

Dietz, W. H., Douglas, C. E., \& Brownson, R. C. (2016). Chronic disease prevention: tobacco avoidance, physical activity, and nutrition for a healthy start. Jama, 316(16), 1645-1646.

Epstein, S. B., Jean-Pierre, K., Lynn, S., \& Kant, A. K. (2013). Media coverage and awareness of the 2010 dietary guidelines for Americans and MyPlate. American Journal of Health Promotion, 28(1), e30-e39. https://doi.org/10.4278/ajhp.120420-QUAL-213

Erinosho, T. O., Moser, R. P., Oh, A. Y., Nebeling, L. C., \& Yaroch, A. L. (2012). Awareness of the Fruits and Veggies-More Matters campaign, knowledge of the fruit and vegetable recommendation, and fruit and vegetable intake of adults in the 2007 Food Attitudes and Behaviors (FAB) Survey. Appetite, 59(1), 155-160. https://doi.org/10.1016/j.appet.2012.04.010

Gu, X., \& Tucker, K. L. (2016). Dietary quality of the US child and adolescent population: trends from 1999 to 2012 and associations with the use of federal nutrition assistance programs. The American Journal of Clinical Nutrition, ajcn135095. https://doi.org/10.3945/ajcn.116.135095

Guthrie, J., Mancino, L., \& Lin, C.-T. J. (2015). Nudging consumers toward better food choices: Policy approaches to changing food consumption behaviors. Psychology \& Marketing, 32(5), 501-511. https://doi.org/10.1002/mar.20795

Haack, S. A., \& Byker, C. J. (2014). Recent population adherence to and knowledge of United States federal nutrition guides, 1992-2013: a systematic review. Nutrition Reviews, 72(10), 613-626. https://doi.org/10.1111/nure.12140

Johnson, N. B., Hayes, L. D., Brown, K., Hoo, E. C., Ethier, K. A., \& Centers for Disease Control and Prevention (CDC). (2014). CDC National Health Report: leading causes of morbidity and mortality and associated behavioral risk and protective factors--United States, 2005-2013. MMWR Supplements, 63(4), 3-27.

Kennedy, E., Meyers, L., \& Layden, W. (1996). The 1995 dietary guidelines for Americans. Journal of the American Dietetic Association, 96(3), 234-237. https://doi.org/10.1016/S00028223(96)00072-7

Kimmons, J., Gillespie, C., Seymour, J., Serdula, M., \& Michels Blanck, H. (2009). Fruit and vegetable intake among adolescents and adults in the United States: Percentage meeting individualized recommendations. The Medscape Journal of Medicine, 11(1), 26.

Kolodinsky, J., Harvey-Berino, J. R., Berlin, L., Johnson, R. K., \& Reynolds, T. W. (2007). Knowledge of current dietary guidelines and food choice by college students: Better eaters have higher knowledge of dietary guidance. Journal of the American Dietetic Association, 107(8), 14091413. https://doi.org/10.1016/j.jada.2007.05.016

Levine, E., Abbatangelo-Gray, J., Mobley, A. R., McLaughlin, G. R., \& Herzog, J. (2012). Evaluating MyPlate: An expanded framework using traditional and nontraditional metrics for assessing health communication campaigns. Journal of Nutrition Education and Behavior, 44(4), S2-S12. https://doi.org/10.1016/j.jneb.2012.05.011

Movassagh, E., Baxter-Jones, A., Kontulainen, S., Whiting, S., \& Vatanparast, H. (2017). Tracking Dietary Patterns over 20 Years from Childhood through Adolescence into Young Adulthood: The Saskatchewan Pediatric Bone Mineral Accrual Study. Nutrients, 9(9), 990.

https://doi.org/10.3390/nu9090990 
Roth, S.E., Gill, M., Chang-Golston, A.M., Crespi, C.M., Albert, S.L., Rice, L.N., Prelin, M.L / Californian Journal of Health Promotion 2018, Volume 16, Issue 2,Pages 1-10.

Ogden, C. L., Carroll, M. D., Kit, B. K., \& Flegal, K. M. (2014). Prevalence of childhood and adult obesity in the United States, 2011-2012. JAMA, 311(8), 806. https://doi.org/10.1001/jama.2014.732

Pirouznia, M. (2001). The association between nutrition knowledge and eating behavior in male and female adolescents in the US. International Journal of Food Sciences and Nutrition, 52(2), 127132. https://doi.org/10.1080/09637480020027000-8

Pivonka, E., Seymour, J., McKenna, J., Baxter, S. D., \& Williams, S. (2011). Development of the behaviorally focused Fruits \& Veggies-More Matters public health initiative. Journal of the American Dietetic Association, 111(10), 1570-1577. https://doi.org/10.1016/j.jada.2011.07.001

Post, R. C. (2011). A New Approach to Dietary Guidelines Communications: Make MyPlate, Your Plate. Childhood Obesity, 7(5), 349-351. https://doi.org/10.1089/chi.2011.0500.post

Prelip, M., Kinsler, J., Thai, C. L., Erausquin, J. T., \& Slusser, W. (2012). Evaluation of a School-based Multicomponent Nutrition Education Program to Improve Young Children's Fruit and Vegetable Consumption. Journal of Nutrition Education and Behavior, 44(4), 310-318. https://doi.org/10.1016/j.jneb.2011.10.005

Produce for Better Health Foundation, Centers for Disease Control \& Prevention. (2007). Our mission and story. Retrieved March 23, 2017, from http://www.fruitsandveggiesmorematters.org/ourmission-our-story

Rafiroiu, A. C., Anderson, E. P., Sargent, R. G., \& Evans, A. (2002). Dietary practices of South Carolina adolescents and their parents. American Journal of Health Behavior, 26(3), 200-212.

Rasmussen, M., Krølner, R., Klepp, K.-I., Lytle, L., Brug, J., Bere, E., \& Due, P. (2006). Determinants of fruit and vegetable consumption among children and adolescents: a review of the literature. Part I: quantitative studies. International Journal of Behavioral Nutrition and Physical Activity, 3(1), 22.

Reedy, J., \& Krebs-Smith, S. M. (2010). Dietary Sources of Energy, Solid Fats, and Added Sugars among Children and Adolescents in the United States. Journal of the American Dietetic Association, 110(10), 1477-1484. https://doi.org/10.1016/j.jada.2010.07.010

Rimer, B., \& Glanz, K. (2005). Theory at a glance: A guide for health promotion (No. NIH Publication No. 05-3896). Washington, D.C.: US Dept of Health and Human Services, National Institutes of Health.

Spronk, I., Kullen, C., Burdon, C., O’Connor, H., \& Connor. (2014). Relationship between nutrition knowledge and dietary intake. British Journal of Nutrition, 111(10), 1713-1726. https://doi.org/10.1017/S0007114514000087

StataCorp. (2015). Stata Statistical Software: Release 14 (Version 14.2). College Station, TX: StataCorp LP.

Story, M., Neumark-Sztainer, D., \& French, S. (2002). Individual and Environmental Influences on Adolescent Eating Behaviors. Journal of the American Dietetic Association, 102(3), S40-S51. https://doi.org/10.1016/S0002-8223(02)90421-9

Tagtow, A., \& Raghavan, R. (2017). Assessing the Reach of MyPlate using National Health and Nutrition Examination Survey Data. Journal of the Academy of Nutrition and Dietetics, 117(2), 181-183. https://doi.org/10.1016/j.jand.2016.11.015

UCLA Center for Health Policy Research. (2014). 2013-2014 California health information survey. Retrieved December 7, 2016, from http://ask.chis.ucla.edu

US Department of Agriculture Food and Nutrition Service. (2012). Choose my plate. Retrieved October 31, 2016, from www.choosemyplate.gov

Wojcicki, J. M., \& Heyman, M. B. (2012). Adolescent nutritional awareness and use of food labels: Results from the national nutrition health and examination survey. BMC Pediatrics, 12(1). https://doi.org/10.1186/1471-2431-12-55

World Health Organization. (2003). Joint WHO/FAO Expert Consultation on Diet, Nutrition and the Prevention of Chronic Disease. Geneva, Switzerland: WHO. 
Wright, J. D., \& Wang, C.-Y. (2011). Awareness of federal dietary guidance in persons aged 16 years and older: Results from the national health and nutrition examination survey 2005-2006. Journal of the American Dietetic Association, 111(2), 295-300. https://doi.org/10.1016/j.jada.2010.10.049

\section{Acknowledgements}

This research was funded by the National Institute of Nursing Research (5R01NR012676) and supported by grants from the National Heart, Lung and Blood Institute at the National Institutes of Health (P50 HL105188 and R25 HL108854). The authors declare no conflict of interest.

Author Information

Sarah E. Roth, MA

Doctoral Student,

Department of Community Health Sciences

UCLA Fielding School of Public Health

650 Charles E Young Drive

26-071 CHS

Los Angeles, CA 90095

Phone: 310-206-3526, Email: selizabethroth@gmail.com 